\title{
A Survey of Women's Social Representations of Aging and Rejuvenation
}

\author{
Maria Cristina Triguero Veloz Teixeira, Flávio Maciel Settembre \\ and Solange Bezerra Leal \\ Universidade Presbiteriana Mackenzie, São Paulo, Brazil
}

\begin{abstract}
The goal of this work was to analyze the social representations that women of three different age groups had about aging, rejuvenating, and methods of rejuvenation. The research was performed in São Paulo between 2004 and 2005. The participants of this research were three groups of women of different ages: 19 to 24 years, 25 to 35 years, and over 60 years. The data were collected by the focus group technique. Data was analyzed using the lexical analysis software ALCESTE 4.5. The main results show a social representation of aging centered on losses and gains. The subjects appraised the possibility of using rejuvenating methods only when it was extremely necessary, because of the health risks that most of them involve. The three groups agreed about natural methods of rejuvenating instead of resorting to invasive methods.
\end{abstract}

Keywords: social representations, aging, rejuvenating, technology

\begin{abstract}
El propósito de este trabajo fué analizar las representaciones sociales de tres grupos de mujeres de diferentes edades acerca del envejecimiento, el rejuvenecimiento y los métodos de rejuvenecimiento. La investigación se llevó a cabo en São Paulo entre 2004 y 2005. Las participantes de la investigación eran tres grupos de mujeres de diferentes edades: 19 a 24 años, 25 a 35 años, y mayores de 60 años. Los datos se recogieron con la técnica del grupo focal Se analizaron empleando el software de análisis lexical ALCESTE 4.5. Los resultados principales revelan una representación social del envejecimiento centrada en pérdidas y ganancias. Las participantes consideraban la posibilidad de usar métodos de rejuvenecimiento sólo cuando era de máxima necesidad, debido a los riesgos de salud que la mayoría de ellos implican. Los tres grupos estaban de acuerdo en el uso de los métodos naturales de rejuvenecimiento en vez de recurrir a métodos invasivos. Palabras clave: representaciones sociales, envejecimiento, rejuvenecimiento, tecnología
\end{abstract}

Correspondence concerning this article should be sent to Maria Cristina Triguero Veloz Teixeira, Universidade Presbiteriana Mackenzie, São Paulo, Brazil. E-mail: mctvteixeira@gmail.com

Finnancial support: Programa de Iniciação Científica (PIBIC-CNPq) da Universidade Presbiteriana Mackenzie. 
The present article represents part of the results from a more extensive research project focused on the study of social representation of science and technology and the dissemination of scientific data to the rejuvenation industry. The subject of this article-aging, rejuvenation, and science and technology in the rejuvenation industry-was approached with two methods: interrogative methods (focus group technique) and associative methods (free word association and successive hierarchical triage tests). Only the results related to the results from the focus group technique are discussed in this article.

Sá (1998, p. 17) criticized the excessive enthusiasm in the approach to social representation in studies of diverse subjects. It has become obvious that, to achieve a psychosociological understanding of a phenomenon in the consensual universe, it must also be studied in the universe informed by scientific practice. We will review some of this data related to the topic of the research project.

According to Kalache, Veras, and Ramos (1987), in 1960, more than half of the people over 65 lived in third world or in developing countries. Demographic data indicate that, from 1980 to the end of the $20^{\text {th }}$ century, nearly three quarters of the increase in the aged population occurred in third world or in developing countries. The group of senior citizens was the age group that increased the most in less developed countries. In South America alone, between 1980 and 2000, an increase of $120 \%$ of the total population (from 363.7 to 803.6 million) was observed. The increase in the population of people over 60 years old was $236 \%$ (from 23.3 to 78.2 million), that is, more than double the percentage of the increase in the population as a whole. In Brazil, specifically, the population of senior citizens will increase about 15 times between 1950 and 2025, whereas that of the population as a whole will increase no more than 5 times in the same period. By 2025, this increase will mean that $1 / 6$ of the population of senior citizens of the entire world, in absolute terms, will live in Brazil. On the one hand, there is a process of massive aging of the population. On the other, research is being carried out in various scientific areas, which seeks to improve the quality of life for people in general, prolonging life expectancy while maintaining ever more youth, although people's chronological age is above 60 years (Imhof, 1987; Oria, Ferreira, \& Santana, 2003). There is a branch of science aimed at finding technologies for rejuvenation, delay of aging, or healthy aging (Flor \& Nascimento-Schulze, 2002; Pagnano, 1990; Velasco, Ribeiro, Bedin, Okubo, \& Steiner, 2004).

Our team investigated people's social representations of aging, old age, and aged persons, between the years 1997 and 2000. The study targets were populations of older people whose age bracket was near the age that is considered a representation of the elderly from images associated with the loss of physical beauty occurring with the passing of time. Some of these participants' attitudes were favorable towards the use of rejuvenation methods (Guimarães, 1997; Veloz, Nascimento-Schulze, \& Camargo, 1999).
Aging, treated as a social, psychological, economical, political and populational phenomenon, is extremely complicated. The changes that the population structures are experiencing, caused by aging of the population in the $20^{\text {th }}$ century, are very diverse. Each country has adopted public, social, and health policies in order to guarantee not only functional health for older people, but also to keep them at home with the least possible responsibility.

Currently, there are comprehensive models of aging that, in addition to being multidimensional, are supported by theories about the course of life that defend a continuous progression of development from birth to death. These theories are related to the ways that society attributes social and personal significance to the biographical passing of time, allowing the social construction of personalities and life trajectories based on a sequence of transitions that are socially marked and differentiated by age (Baltes, 1987). In the attempt to understand aging within this perspective of the theories of the course of life, this work, analyzes the definition of aging associated with the viewpoint of rejuvenation. This was proposed in order to discuss some social forms of representing and attributing images, by means of two processes that are currently being researched by scientists and extended by the media: aging and rejuvenation. It is noted that the focus adopted is not intended to reduce aging-related issues merely to aspects of physical and aesthetic matters. When the topic of rejuvenation was included as the other subject to be investigated by the social representation approach, the need to refer to topics of aesthetic medicine and the media inexorably arose, among others. However, the data analyses from those particular findings are more extensive.

In general, the practices of cosmetic and aesthetic medicine are becoming ever more frequent across the globe (Coleman \& Brody, 1997; Draelos, 1991; Odo \& Chichierchio, 1998). Thus, believing in technological development for rejuvenation, people undergo risky surgical processes in search of prolonged physical youth. One of the social and scientific conditions that have promoted this is the development of new technologies, especially those in the technical field of rejuvenation or delay of physical aging, springing from current advances in medical sciences (Oria et al., 2003; Velasco et al., 2004).

As noted by Nascimento-Schulze (2000), ordinary people react to technological advances in different ways: sometimes, with a mixture of reverence and reserve, approval and discernment, and, others, with enthusiasm or disapproval.

To study such a controversial subject as rejuvenation was difficult for the researchers. It is a topic strictly related to other subjects such as the media, publicity, medical science, and conversations about daily life, among others. The decision about the ideal sample to be able to access these representations was not an easy task. We are currently living in a very peculiar time for the subject that we were interested in researching. The technical revolution in the 
field of rejuvenation that arrived with the second half of the $20^{\text {th }}$ century and the $21^{\text {st }}$ century is experienced profoundly by various generations. Women occupy a special place in these generations. They are active participants in social communication practices, having to understand scientific knowledge on the subjects of aging and rejuvenation. Beyond these aspects, was the awareness that the research topic is a part of daily communication and certain personal practices of many women who, besides belonging to different age brackets, are living in the same decades. Thus, our interest was aroused to determine how these women from different generations currently consider the subjects of aging and rejuvenation. This brings us to the date in which the study was performed, 2004-2005. The goals of the work were to collect the contents of social representations that women of various age brackets build of aging, rejuvenation, science and technology in the field of rejuvenation.

The theoretical framework of this work was the theory of social representation, with emphasis on which fields constitute a social representation. When a social representation of some scientific subject that is of interest to a group is constructed, it is the product of multiple daily exchanges and discussions that are eventually considered common sense. This representation acts in the interface of social and cognitive phenomena, from communication and from social thought (Moscovici, 1978). In this sense, a social representation is a form of socially elaborated and shared knowledge, which has the practical goal of constructing a reality that is common to a group of individuals (Jodelet, 2001).

Moscovici (1978) further notes that social representations are particular forms of knowledge, whose function is to make the unknown or unfamiliar subjects of individuals' conversations become familiar or known to them. These representations remodel and reconstruct the elements of the average environment in which these individuals function. With regard to the construction of a social representation, Moscovici established that it is configured in three fields or dimensions: information, field of representation or image, and attitude.

The field of information refers to organization of knowledge that a group has about a subject that is socially represented and shared. In order to discuss a subject and form a representation thereof, a group needs certain basic knowledge concerning it (preferably, scientific knowledge that is presented in the media). Knowledge of this kind varies in quality and quantity, from individual to individual, and from group to group. Before forming a social representation of a new anti-wrinkle cream, for example, people acquire information about the topic from the media, research, books, or even daily conversations that may be appropriate to the subject. The field of representation includes the idea of an image, a social model that specifies and limits the content of the proposals about a necessary aspect of the subject of the representation.
And attitude focuses on the global behavioral orientation related to the object of the social representation. Attitude can also be defined by the individual's response to the subject, or preparation for action. The individual may have a favorable, unfavorable, or neutral attitude in relation to the social consensus on the subject (Moscovici, 1978). Although they have a symbolic origin within each individual, attitudes are anchored in the social relationships that generate them, organized in many different ways, thus forming various social representations, as also occurs with opinions and stereotypes.

For a long time, the media has been influencing people's attitudes toward a wide range of social, cultural, and scientific subjects and concepts (Almeida \& Mattos, 2005; Fischer, 2002). For example, many newspapers currently publish polemic subjects (drugs, abortion, and genetically modified organisms, among others), with interviews and varied testimonies - in favor, against, or neutral-about the subject. Women's magazines, which have an adult readership, frequently explore subjects related to plastic surgery, rejuvenation techniques, aerobics, and physical exercise to maintain a socially acceptable physical appearance, even displaying in these articles women who appear young regardless of their age. There has been much literature since the $20^{\text {th }}$ century showing the intense technological treatment that photographs undergo to produce deceptively perfect models who waken the desire of the public consumer (Brittes, 2000; Grangeiro, 1998; Tacca, 2002).

To conclude, we return to the research field of the present study, seeking to relate some theoretical aspects to a completed empirical investigation. On the one hand, the statistical data show that there is a world tendency toward greater life expectancy (Imhof, 1987; Kalache et al., 1987; Siqueira, Botelho, \& Coelho, 2002; Veras, Ramos, \& Kalache, 1987). On the other hand, according to Morin (1987), society is being pushed towards a movement of "geronticratization" (sic), and this often, corresponds to attitudes of "pedocratization" (sic). The topic of youth is not relegated only to science, but also to the young, and to those who have already grown old. Many people are not prepared for old age, but instead, struggle to maintain their youth. For some people, it would be a sin to assume the condition of age within the normal standards that this condition imposes (Morin, 1987).

More subtle losses are not always objectified in the image of aging, for example, the cellular and physiological alterations that lead to the decline of the body's efficiency and the increase of illnesses. For many people, whether or not they are concerned about aging, it seems that the most importance aspect is to delay wrinkling or to achieve a nearly perfect body. To achieve this, they assume certain social practices in search of technologies (surgery, cosmetics, massages, substances based on embryos or regenerative juices) that delay wrinkles and flaccidity (Velasco, et al., 2004). 


\section{Method}

\section{Participants}

The sample was made up of three groups of participants. The first group was made up of 18 women between 19 and 24 years, university students in their $2^{\text {nd }}$ year of Psychology at the Mackenzie Presbyterian University. These participants' financial income was between $\mathrm{R} \$ 1,000.00$ and $\mathrm{R} \$ 3,000.00$ (lower middle class); most of them (98\%) were single, none of them had children, and 50\% were Catholic. The second group was made up of 17 women between 25 and 35 years, university students in their $5^{\text {th }}$ year of Psychology at the Mackenzie Presbyterian University. These participants' financial income of was between $\mathrm{R} \$ 1,000.00$ and $\mathrm{R} \$ 2,000.00$ (lower middle class); $58 \%$ were single, $32.3 \%$ married, $82.35 \%$ had no children and $47.5 \%$ were Catholic. The third group of 25 women was over 60 years old; they attended activities at the Open University of Useful Time (UATU) of the Mackenzie Presbyterian University in São Paulo, and activities of the Nucleus of the Third Age of the Social Service of the Commerce Social Service (SESC) of the Consolação district of São Paulo. The activities of these two institutions (UATU and SESC) are aimed at pedagogical projects for the elderly in order for them to continue their education, develop sociocultural abilities that foster their self-knowledge and social integration, with a view to full exercise of citizenship. A large part of the participants in the sample (80\%) did volunteer work in the community at the time in which the data were collected. The average financial income of these participants at the time of data collection was between $\mathrm{R} \$ 1,000.00$ and $\mathrm{R} \$ 2,000.00$ ( $48 \%$ of the total of this third group). Also in this third group, $30.5 \%$ were married, and $27 \%$ were widows. The majority were retired (39\%) and many of them (27\%) owned a home; $76 \%$ had children and $75.75 \%$ were Catholic.

Six focus groups (each of the three groups of participants was divided into two focus groups) were created with 9 to 10 participants in each one. All of the groups met some of the inclusion criteria for the sample: a) structured or organic real group, which means that there was a relationship among the participants of the groups based on some activity, duty, interest, or responsibility that was common to all, bringing them into personal contact; b) taxonomic group, in which the subjects were classified according to the variable age.

\section{Measuring Instruments and Procedure}

The instruments for data collection were selected for their capacity to examine contents of social representation. An interrogative focus group technique was chosen that is widely used and readily available to the researcher when the object is to identify representational contents, in a primary research phase. The technique allows simulation of conversation by which social representations focused on a specific subject in daily life are brought up.
Independently from the external focus of the discussions (aging, rejuvenation, rejuvenation methods), there were other topics on which discussions were focused, such as knowledge about science and technology to delay aging, individual practices related to the search, acceptance, or rejection of rejuvenation treatments, and others. All of the technical discussions of the focus group were centered on the following topics: aging, rejuvenation, rejuvenation methods, eternal youth, and medicinal advances in rejuvenation. All the group dynamics were carefully observed. Each focus group lasted for a maximum of 90 minutes, with an average of 75 minutes. The discussions were recorded with two recording devices in the center of the circle formed for the discussion. Recording was done in the following manner: An interval of time was given between the beginning of the recording with one recorder and the beginning of recording with the other recorder, so that the initial presentation was recorded only on one. In this way, when the tape was being flipped from one side to the other in one recorder, the recording was not interrupted because the other recorder was still functioning. Each of the recorders was placed at opposite ends of the circle of people to reduce the distance between the recorders and the participants.

The following analyses were conducted on the content from the groups: an accurate transcription of both tapes was made, the transcription was revised and the statements clarified, the transcription was adapted to the standards of the ALCESTE software (Reinert, 1990), the coordinators' words were removed, the final transcription was revision, archives were organized and the textual material was treated with the ALCESTE software, which aided the quantitative analyses of textual materials.

The computer program ALCESTE presumably operates following these steps:

1. Reading the text and calculating the dictionaries: preparation of the text body, recognition of initial contextual units (ICUs), and separation of the elementary contextual units (ECUs), small segments of the text of varying size; the order of appearance within the text is respected in the analysis. The words are grouped according to their roots. The program distinguishes between instrumental words (articles, prepositions, and conjunctions), essential words for the organization of the text, and analytic words (nouns, verbs, adjectives), which define the representational content.

2. Calculation of the data matrix and classification of the ECUs; classification of the ECUs according to their respective vocabulary and separation of these ECUs according to the frequency of the reduced forms in the text, with the help of frequency matrices, that cross the reduced forms of the body and the ECU. Performance of descending hierarchical analysis to separate the ECUs into various classes according to the vocabulary that forms them, so that the greatest possible value in an 
association test can be obtained by $\chi^{2}$ (cluster analysis). The same process is performed with the obtained classes, until the vocabulary of the ECUs of all of the classes is homogeneous. At this point, the ALCESTE program offers a table that presents the distribution of the classes formed that allows a primary compression of the obtained classes, principally by the characteristic vocabulary (lexicons), and by their words with asterisks (descriptive value of the participants according to group).

3. Complimentary calculation: this stage is an extension of the second. Based on the classes of ECUs chosen, the program gives the most characteristic ECU in each class and contextualizes the occurrences of the vocabulary that were typical in each one.

The lexicographical analysis of the textual material from the focus groups was completed with a single body that contained all of the conversations of the seven focus groups. Two elements justify the conjoint analysis of the data. One of them is technical: the conversations from the separate groups do not guarantee sufficient textual material to process the data processing individually (by group steps) with a computer program. The other element entails an advantage of the ALCESTE program, which, in one of the steps of data processing, classifies all of the textual material of the ECUs according to criteria of frequency and association based on a $\chi^{2}$ test. The program presents a distribution of classes, whose vocabulary is homogeneous and in which the principal descriptive variables are distinguished (in this case, the groups that contribute the most to the formation of the class). The program presents a descriptive report of the typical ECU for each class that enables differentiation of the segments of text (ECU) in each of the classes or contexts - types, as Nascimento-Schulze and Camargo (2000) note.

\section{Results and Discussion}

\section{Summary of the Data Processing of the Text Body Without the Interviewer's Words}

Data processing with the ALCESTE software was performed with six ICUs (which means that the data from six focus groups were processed). Hierarchical descending analysis divided the entire body into 606 ECUs. In these 606 ECUs were 3195 different words or terms. After reducing the terms to their roots, 1921 analytic words and 352 instrumental words were obtained. The 1921 analytic words occurred 9239 times, with each word contributing to the construction of the body 8 times on average. In the hierarchical descending analysis, 489 ECUs were found, of the 606 into which the body was initially divided. In other words, hierarchical descending analysis considered $50.69 \%$ of the total of the ECUs that the body presented for the analysis, leaving $19.31 \%$.

As can be seen in Figure 1, in which the distribution of the classes is presented (corresponding to the Pass of the hierarchal descending classification-B3_rcdh1 in Figure 1 ), there were two divisions of the body. One of these divisions originated the classes 1 and 3 (whose ECUs presented contents related to the topics of aging: gains and losses (Class 1) and rejuvenation methods: benefits and risks (Class 2), as can be seen in Figure 2.
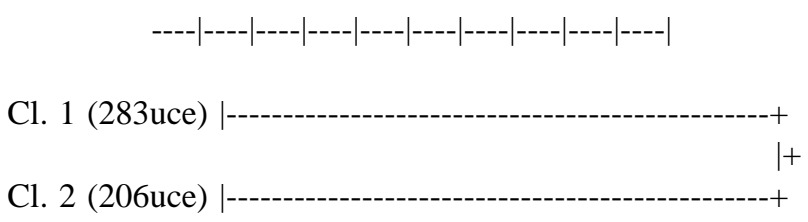

Figure 1. Table of stable classes (from B3_rcdh1): Hierarchal descending classification. Table of stable classes (from B3_rcdh1). São Paulo, 2005.

Next, the ECU percentages that each of the classes of the table contained after processing of the data with the ALCESTE software are described: Class 1: $51.87 \%$ of the total ECUs of the body; Class 2: $42.13 \%$ of the total ECUs of the body.

In the measure in which the context-types or classes are discussed, examples of the ECUs are presented that belong to the class that typifies the group. These ECUs are classified in two ways: when there are statements common to various participants in the ECU, it is designated as a statement common to the group, and when the statement is referred to in only one participant, this indicates that the statement that arose within the group ${ }^{1}$ is related to only one participant.

The class was made up of with 283 ECUs and its content comprised predominantly statements from the focus groups completed by the women over 60 years old. It is the class that we call "Aging: gains and losses," whose content was about the advantages and disadvantages of the process of aging and the phase of old age. The words of greatest frequency and statistically significant association with this class, together with the following exemplified ECUs, show the structural cognitive coherence between of the name of the class and its contents, for example: house, old, life/to live, experience, believe, youth, age, difficult, work/to work, happiness/happy, son, to die, sad/sadness, family, and good, among others.

1 In each ECU, the words that are listed in the classes of Figure 2 are emphasized. 


\begin{tabular}{|c|c|c|}
\hline WORD & FREQUENCY & $\chi^{2}$ \\
\hline To believe & 9 & 6.67 \\
\hline Happiness/happy & 12 & 6.5 \\
\hline Grandparents & 9 & 4.32 \\
\hline Good & 14 & 4.33 \\
\hline House & 32 & 17.41 \\
\hline Children & 10 & 5.04 \\
\hline Difficult & 12 & 4.58 \\
\hline Aging & 20 & 4.09 \\
\hline Eternal/eternally & 13 & 9.72 \\
\hline Family & 11 & 3.98 \\
\hline Son & 17 & 10.25 \\
\hline Age & 42 & 7.61 \\
\hline Elderly & 12 & 8.95 \\
\hline Young & 33 & 10.84 \\
\hline Youth & 24 & 15.71 \\
\hline Marvelous & 17 & 12.82 \\
\hline To die & 17 & 8.10 \\
\hline Grandchild & 11 & 8.19 \\
\hline Feel & 17 & 8.10 \\
\hline Technology & 17 & 4.79 \\
\hline Work/to work & 13 & 9.72 \\
\hline Sad/sadness & 9 & 4.32 \\
\hline Old & 28 & 8.98 \\
\hline$\underline{\text { Life }}$ & 39 & 4.32 \\
\hline Living/to live/life & 24 & 11.28 \\
\hline $\begin{array}{l}\text { Group of women } \\
\text { over } 60 \text { years old }\end{array}$ & 81 & 32.61 \\
\hline $\begin{array}{l}\text { Group of women } \\
\text { over } 60 \text { years old }\end{array}$ & 69 & 7.90 \\
\hline $\begin{array}{l}\text { Group of women } \\
\text { between } 25 \text { and } \\
35 \text { years old }\end{array}$ & 51 & 8.48 \\
\hline
\end{tabular}

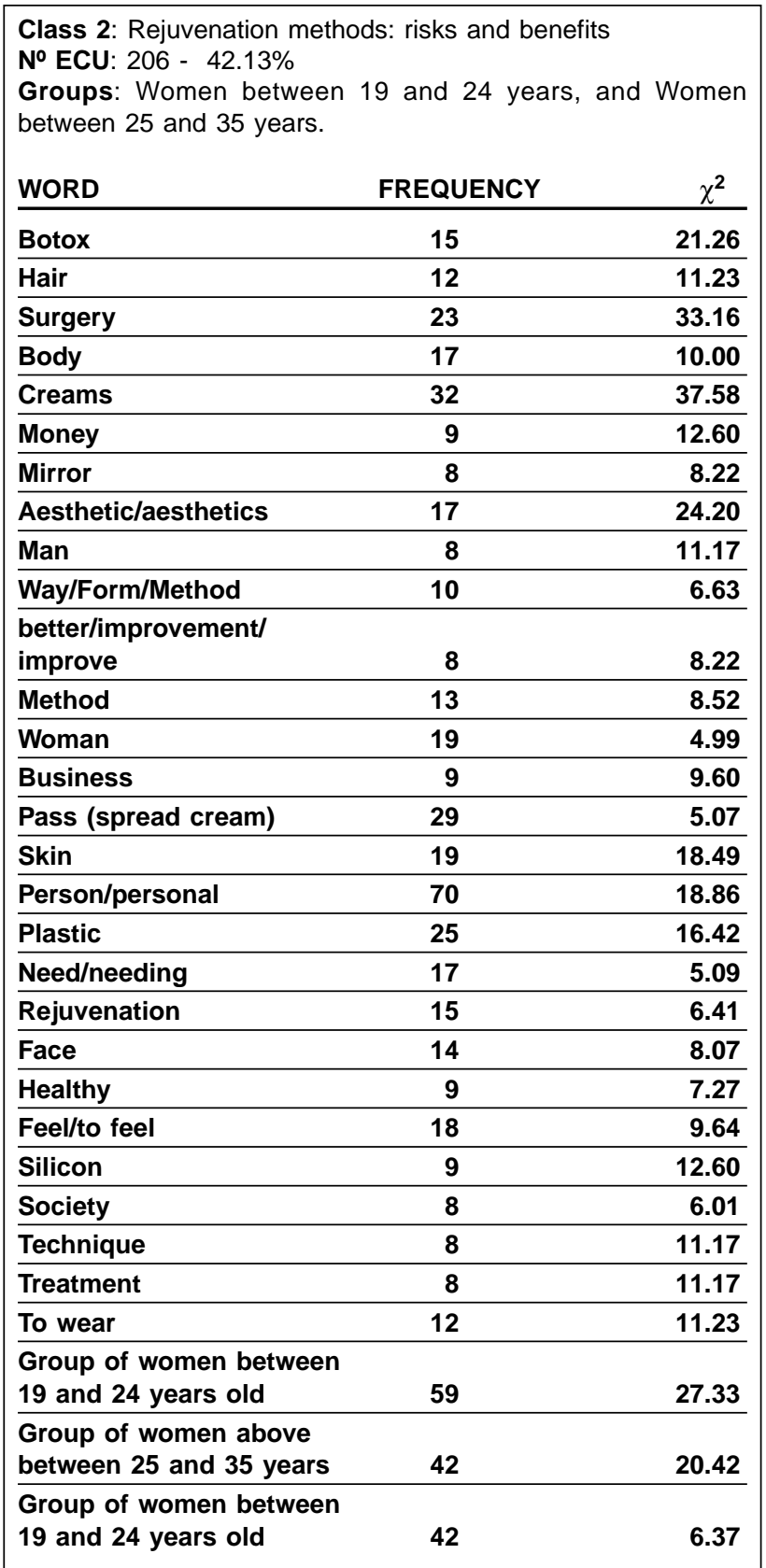

Figure 2. Distribution of classes ${ }^{2}$.

According to the analyzed body, it can be observed that in Class 1 , the participants agree that nowadays, in general, the elderly are the holders of wisdom, life experience, knowledge and information that were gained through experiences acquired throughout their lifetime. Many gains in terms of families created, more free time for social enterprises, and to care for grandchildren, among others, were mentioned. For example, in the ECU below, an image (content) can be observed that indicates a dimension of the field of social representation that the group of women over 60 made on the subject of aging I say that life is a little more difficult because now I have to fend for myself, but I am happier at the age of sixty-two, catching the bus and all (ECU of only one subject participating in the group of women over 60$)$.

2 It can be seen in the classes that there is more than one group of participants of the same age bracket. Within each age bracket, 2 focus groups were created, totaling 6 groups. 
I think I am more responsible, but it's better because I have no more responsibilities like before with children and with grandchildren and all (ECU of only one subject participating in the group of women over 60).

Regarding losses, the participants mentioned some difficulties they have with the process of aging, principally, in aspects associated with health and with some attitudes of social indifference toward the elderly, which can be observed in the ECUs below.

I think now, at the age of sixty-two, I would say from the start that it was difficult, is difficult because I left the good part. Now I have no more good part. Now I must open the elevator door by myself, I have nobody to open the door. But I think now, looking back over my sixty-two years I think that my old age gave me greater wisdom (ECU of only one participating subject in the group of women over 60 years).

Now it's no good anymore, now that I am sixty-two, I have to concentrate more, and life is much more difficult, life is harder, pain comes more quickly, I'm happy for those who have no pain, I have pain in my spine and everywhere (ECU of only one subject participating in the group of women over 60 years).

As Moscovici stated (1978, p. 27), to represent does not only consist of selecting, achieving a specific goal, in addition to a supplement of subjective soul. In fact, the participants in the study did not select only the classic attributes of losses that have traditionally been attributed to old age. In the words of these women, contents and images (dimensions of the image in the social representation) predominated that are reminiscent, as Moscovici (p. 58) notes, of a conceptual nature of this phase of life. Old age, under the prism of how it should be and how it is. We should remember that these women are already experiencing this stage of life. Beyond making available the scientific and daily information about this phase of life, they are already in the condition of elderly. There were images in the listed ECUs that show a social representation of aging and old age in which the losses are close to the limits of the reserve capacities and where the balance of gains and losses becomes less positive, according to one of the seven presuppositions of the model of successful aging (Baltes, 1991). We hypothesize that, beyond the content that can be classified from the viewpoint of the dimension or field of images, other contents appear to point to the dimension of information. This is because some of the statements contained in the ECUs not only follow Baltes' model $(1987,1991)$, but also the model of Santos and Belo (2000), in which the process of aging is considered natural and unquestionable and emphasizes the valuable experience of the elderly, focusing on the positive aspects of old age. Following the principle of seniority, the value and utility of the elderly would be in acknowledged by the group, and this would allow them to maintain some aspects of their psychosocial identity. It is obvious that the element of experience alone does not guarantee satisfaction in old age, due to the particular heterogeneities in the course of people's lives. Satisfaction would also depend on the life history of each one and how they deal with the adversities of their life. This knowledge was observed, both in the statements of the young participants and in those of the participants over 60 years old that were classified in this Class 1. For example:

There are people who want to grow older. And there are people who reach old age, without so much disposition. And without so much happiness, too. And, there happiness ends, because at times these people grow old and don't see their grown children or their grandchildren (ECU of a statement common to the group of women between the ages of 19 and 24 years).

The psychosocial complexity involved in the analysis of the process of aging manifests in some of the images of the social representation of this Class 1 . The image of losses and gains was identified in ECUs in that it was seen as nostalgia for the distant past, where everything seemed to be idealized, but it was solidified in many of the statements about daily life from the women who were already over 60 . The following textual phrase can illustrate this.

I cannot say that I am happier today than in the past, because I am divorced, but I think that at every age, at times I remember longing for when the children were little, because I have two children and a grandson (ECU of a statement common to the group of women over 60 years).

According to the previous discussions, it was perceived that the emphasis that these participants made on the process of aging and the condition of old age is diverse. In it, there is no predominance of images of physical aspects, especially aesthetic aspects. Overall, the terms and statements of these women about these subjects of rejuvenation were not characterized in a context-type or class predominant for this group. The emphasis revolved around the theme of aging and the process of growing old, whose consensual contents for them appeared in the ECUs described. The contents point to a process that is natural, or at least should be, as it is part of the very cycle of life. However, it seems to happen in various manners in the subjectivity of the individuals. Some people of advanced age felt they were still young at heart, but with bodily limitations and pains (which are more frequent with advanced age), which make obvious the passing of time. We see an ECU of this class that belongs to a woman aged between 25 and 35 in which there is a representation of old age with a predominance of contents in which subjective aspects and physical deterioration (pain and illness) are prioritized. Likely, this positive and unrealistic image is due to the age of the participant:

I think she is young, I think she is young, she doesn' $t$ ' want to die, she has a youthful spirit, now without doubt, if it were only for appearances, she doesn't seem young, but if it's about youthfulness, I believe youth is eternal (ECU of only one subject participating in the group of women between 25 and 35 years old). 
There are people who feel old long before true old age really begins. Some of the people try to maintain an appearance compatible with their age while maintaining a young mind, including the use of rejuvenation techniques of the broadest variety in order to delay aging. In this study, for instance, it was confirmed that the majority of the participants of the three research groups showed positive attitudes towards the use of rejuvenation techniques. In the case of the youngest women, $83 \%$ were in favor of their use, although $99 \%$ did not yet use any specific technique. Of the group of women between 25 and 35 years, $91.17 \%$ also had a favorable attitude, and $17.64 \%$ were already using rejuvenation treatments. Finally, except for a small percentage, the elderly women were also in favor of the use of these processes $(72.72 \%)$ and $15.15 \%$ already used some technique to delay aging or achieve actual rejuvenation.

The above data, beyond other contents of the statements of the focus groups, lead one to conclude that, in general, the women over 60 years old who participated in the study seem to confront the life phase they are undergoing adaptively. The majority of them are active, participate in social community groups, do physical exercise, help their own children in the care of their grandchildren, and attend university programs directed especially at the elderly population. According to Santos and Belo (2000), using a defensive strategy, the participants dichotomize the physical aspects from the subjective aspects (the spirit). They do not view themselves as old in the sense that they are active, functionally independent, have a positive attitude, and, finally, have a "young spirit."

Other contents of the consensual social representation showed images concerning some discomfort with the fact that the media presents a preconception of old age: an image in which old age is not socially valued and which brings us to another dimension of the field of social representation:

Because the connotation of old isn't cool. So even we catch ourselves at times using the language, because we have to be young in spirit, because it is better to be young in spirit than old (ECU of only one subject participating in the group of women between 25 and 35 years old).

The previous ECU reminds us of an example of symbolic position of the type of social representation that, according to Doise (2001), often serves as a background for other symbolic positions that, embedded in various social relationships, can lead to stereotypes.

Many of these stereotypes are broadcast in the media (Grangeiro, 1998). As Codo and Senne (1993) point out, they can lead to social practices that reflect an exaggerated narcissistic process that places the body at the center of attention. Morin (1987) emphasizes that, in current society, what is valued most is the rejuvenation that people can maintain despite the approach of old age. A pejorative media propagates the notion that anything that is old is of no value, a negative connotation that generates in many people the need to maintain this youthful spirit. Old age and topics related to the elderly or aging have, for a long time, been socially constructed based much more on the losses than the gains. As predicted by Santos and Belo (2000), from this viewpoint, in some social environments, to be old corresponds to illness, uselessness, and conservatism, attributes that negatively stereotype old age. At the same time in which these losses are emphasized, the media values youth, a youthfulness that is indicative of modernity. It is likely that the propaganda systems have devalued old age, contributing to more symbolic viewpoints that are observed in some of these participants' statements about injuries with regard to society or illusory images that to be young is better (Fischer, 2002; Oria et al., 2003).

Class 2 consisted of 206 ECUs and the analysis of the content of the focus groups came mostly from the statements of the groups of young women between 19 and 25 and 25 and 35 years old. This class was denominated "rejuvenation methods: risks and benefits," and involved principally discussion of the advantages and disadvantages of the use of rejuvenation methods.

Nascimento-Schulze and Camargo (2000), referring to empirical-analytical and theoretical-methodological plans of a social representation, stated that, at the empirical-analytical level, the structure of the words and reoccurrence of these same words as linguistic elements correspond to the elements of a social representation on the theoretical plain. As can be observed in Figure 2, some of the linguistic elements (words) that had a statistically significant association with Class 2 indicate various contents related to the dimension of information on rejuvenation methods (botox, surgery, plastic surgery, creams, silicon). Other words and ECUs that were discussed afterwards point to social aspects involved in the acceptance or rejection of these methods, because of their cost or because of individual attitudes in favor or against their use. It is observed that the word "person/personal" occurs with a high frequency in Class 2 in Figure 2 (frequency $=70$ ).

The terms of this class showed that, among the youngest women in the sample, there were cautious attitudes about the possibilities of the use of rejuvenation methods. In the statements of the focus groups, there were contents that show concern about the danger of undergoing a surgical procedure, which shows a critical attitude towards the media. Although the damage of these techniques has been cited before, the data show us that some women already had used the techniques (1\% of the group of subjects between 19 and 24 years; $17.64 \%$ of the group between 25 and 35 years, and $15.15 \%$ of the group of women over 60 years). According to Moscovici (1978), attitude indicates the global orientation towards the object of social representation, and he even says that attitude is the most frequent: a person who is informed and presented with a specific topic generally takes a stance. Some of these stances seem implicit in the above data about the use of these techniques, as well as the following ECU: 
Today I wouldn't use any rejuvenation technique for myself. I don't know if I would use it. I think it depends on the aggressiveness. I wouldn't have a liposuction; that is something that causes pain, and more so in the post-operative phase. But that botox I find interesting (ECU of a statement common to the group of women between 19 and 24 years old).

You peel off the skin. Afterwards, we're going to use a cream that I think improves. My skin improved much more with the treatment. How can it not? The skin treatment exists. Now, this business of peeling to keep the flesh alive, I don't want that (ECU of one subject participant in the group of women over 60 years old).

Confirming the statement of Nascimento-Schulze (2000), who said that one of the characteristics of our times is that ordinary people are reacting to technological advances in various ways, it can be seen in the above ECUs that the attitude towards these rejuvenation methods is much more unfavorable than favorable. As Doise (2001) points out, the statements of the research participants reveal, not only attitude about these technological advances in favor of rejuvenation, but also the entire dynamic of social representations of this topic. One may also note the information that the participants seem to have about the options of rejuvenation methods that are available on the market.

I think that cream is good. Now, to keep undergoing so many surgical operations, I don't agree. And, there are various techniques, creams, massages, and this I even find healthy; they have other purposes, but there are methods that shock you. My friend went to the clinic and it was silly; she asked to increase the shock; she didn't even care about the pain she felt. She wants to lose fat at any cost (ECU of statements common to the group of women between 19 and 24 years old).

I think these methods are good if they make you feel better, not necessarily rejuvenated. I want to stay pretty, like a woman of 30 , not pretty like a 15 -year old girl (ECU of only one participant in the group of women between 25 and 35 years).

Currently, the messages in the media about the topic of rejuvenation have reached a level of organization such that had been passing throughout time of messages that were contradictory, and have become more complex, with the clear intention of propagation and propaganda that can be identified in the media submitting them (Doise, 2001; Jodelet, 2001; Moscovici, 1978, 2003). It is likely that these current modes of communication in which this topic is transmitted and divulged have contributed to the existence of some lexical contents of Class 2 in which some ECUs reflected that it is currently necessary for women to always be pretty. This representation justifies the social practice of many women in their on-going search for alternatives to improve their aesthetic appearance (Velasco et al., 2004). In some of the statements of these younger women, there are indicators of a group consensus about the reasons behind certain favorable attitudes and behaviors towards the search for rejuvenation methods. In this case, the attributions of causality of the behavior of seeking these methods are related to aspects of the social environment and media (Moscovici, 2003). For example:

Principally the woman, I think. Not that men haven't also had it, but the woman, she needs that, she needs to be pretty, she needs to have great breasts, she needs to have firm breasts, she needs to have liposuction to remove fat around the stomach. I think this is mostly societal (ECU of only one participant in the group of women between 25 and 35 years old).

Another important factor is the information that these women, especially the young ones, have about the high price of rejuvenation methods. They believe that there are various rejuvenation alternatives such as creams, massages and very sophisticated techniques. The use of a specific method has to be according to the individual's limits, as much the economic limits as those related to subjective values, the element of individual well-being was very important for them, regardless of whether or not they used a rejuvenation method.

[...] but if tomorrow I could not use a cream on my face, I'm not going to kill myself because I can't, I don't have money to buy a cream to put on my face, I think it's a matter of limits, of knowing that you're going to be happy without that, if you can, great, but if you can't (ECU of only one participant in the group of women between 25 and 35 years old).

This information shows a real image of aging and rejuvenation in which the influence of the media is not mechanical. There is an evaluation of the topic that is sometimes presented differently or similarly among the subjects of the research groups and is likewise also different or similar among other social groups and even other cultures.

\section{Conclusions}

The groups participating in this research live in a society impregnated with information from the media in which various messages about old age and rejuvenation prevail. Sometimes, these messages can be harmonious and extensive, from the psychosocial point of view, to convey ideas about the complexity of the process of human aging, especially of old age. Other messages are biased even presenting negative preconceptions in which being old is not accepted, the cult of youth is defended, as is the indiscriminate use of rejuvenation methods. Learning the contents of the social representations about aging, rejuvenation, and science and technology aimed at rejuvenation in these women of different generations who live in the same society represents a modest contribution 
to social psychology. Although the sample was not representative, the choice of the participants revealed the contents of social representations of the relevant topics in groups with diverse social and psychological characteristics, taking into consideration the age brackets of the participants. These women live in a time in which a vast amount of scientific information is available about aging, rejuvenation, and rejuvenation methods, which is disseminated through various forms of the press. This information is interpreted, reconstructed, and re-presented in the groups according to the various filters that these groups create. On the basis of this assumption the study may have contributed to presenting these contents of social representation in women of generations that were born in the 1930s and women who were born in the $70 \mathrm{~s}$ and $80 \mathrm{~s}$, under social, cultural, scientific, and technological influences that were very different among them.

The data from the research show that to study a topic such as rejuvenation is of extreme relevance to studies on aging. Aging can be achieved well when there is an adequate balance between losses and gains. It is likely that rejuvenation may be a part of this conquest of demographic aging of populations if and only if, it is conceived as a central strategy in healthy behavior throughout the course of a person's life.

From these results, a question arose that can orient future research of the same topic addressed in this study: how would women of the same age brackets, not university students, not linked to university education programs, represent aging and rejuvenation science and technology? What is the scientific alphabetical index that women have of the process of human aging?

\section{References}

Almeida, J.R.A.R., \& Mattos, Z. P. B. (2005). Illusory seeds. Environment and Society. 8, 101-120.

Baltes, P.B. (1987). Theoretical propositions of life-span developmental psychology: On the dynamics between growth and decline. Developmental Psychology, 5, 611-626.

Baltes, P.B. (1991). The many faces of human aging. Toward a psychological culture of old age. Psychological Medicine, 21, 837-854.

Brittes, O. (2000). Children of magazines (130/1950). Education and Research. 26, 161-176.

Codo, W., \& Senne, W.A. (1993). What is the body (latria). São Paulo: Brazilian.

Coleman., W.P., \& Brody, H.J. (1997). Advances in chemical peeling. Dermatology. Clinics, 15, 19-25.

Doise, W. (2001). Attitudes and social representations. In D. Jodelet (Org.), Social Representations. (pp. 187-204). Rio de Janeiro: Editor of the State University of Rio de Janeiro.

Draelos., Z.K. (1991). Cosmetics in dermatology, Porto Alegre: Medical Arts.
Fischer, R.M.B. (2002). The pedagogical device of the media: Education methods in (and by) TV. Education and Research, 28, 151-162.

Flor, E., \& Nascimento-Schulze, C.M. (2002). Social representations of sexuality: A study of women of the third age. Review of Human Sciences: Themes of Our Century - Special Thematic Series 2002 Social Representations: Methodological Questions 1, 81-94.

Grangeiro, C.D. (1998). The arts of a business: In the world of 19th century photographic techniques. Brazilian Review of History, 18, 185-205.

Guimarães, M.C.T.V. (1997). Old age: Loss or gain? Masters dissertation, Department of Psychology of the Federal University of Santa Catarina.

Jodelet, D. (2001). Social representations. Rio de Janeiro: Editor of the State University of Rio de Janeiro.

Imhof, A. E. (1987). Possible consequences of increasing life expectancy in Brazil: The perspective of a European historical demographer. Review of Public Health, 21, 447465.

Kalache, A ., Veras, R.P., \& Ramos, L.R. (1987). Aging of the world population: A new challenge. Public Health Review, 21, 200-210.

Morin, E. (1987). Mass culture in the 20th century: The spirit of the times 1: Neurosis, ( $7^{\text {th }}$ ed.). Rio de Janeiro: Forense Universitária.

Moscovici, S. (1978). The social representation of psychoanalysis. Rio de Janeiro: Zahar.

Moscovici, S. (2003). Social representations: Investigations in social psychology. Petrópolis: Voices.

Nascimento-Schulze, C. (2000). Representations of nature and the environment. Review of Human Sciences, Special Edition: Social Representations and Interdisciplinarianism, 3, 63-77.

Nascimento-Schulze, C., \& Camargo, B.V. (2000). Social psychology, social representations and methods. Themes in Psychology from SBP, 8, 287-299.

Odo, M.E.V., \& Chichierchio, A.L. (1998). Practices in cosmetic surgery and aesthetic medicine: Basic surgical procedures. São Paulo: Tecnopress.

Oria, R.B., Ferreira, F.V.A., \& Santana, E.N. (2003). Study of alterations related to age in human skin using histomorphometrical and autoflorescent methods. Brazilian Annals of Dermatology, 78, 425-434.

Pagnano, P. M.G. (1990). Aging of the skin and consequences. Brazilian Journal of Psychology, 39, 37-41.

Reinert, M. (1990). ALCESTE: A methodology for analysis of textual data and an application. Bulletin of Sociological Methodology, 28, 24-54.

Sá, C.P. (1998). Construction of the research object in social representations. Rio de Janeiro: Editor of the State University of Rio de Janeiro - EdUERJ.

Santos, M. de F.S., \& Belo, I. (2000). Various models of old age. Semi-annual Review of the College of Psychology PUC - RS, 31, 31-48 
Siqueira, R.L., Botelho, M I.V., \& Coelho, F.M.G. (2002). Old age: Some theoretical and conceptual aspects. Collective Health and Science, 7, 899-906.

Tacca, F. (2002). Bororo rituals and festivals: Construction of the image of Indian as "savage" in the Rondon Commission. Review of Anthropology, 45, 187-219.

Velasco, M.V.R., Ribeiro, M.E., Bedin, V., Okubo, F.R., \& Steiner, D.(2004). Rejuvenation of the skin by chemical peeling: Approach in phenol peeling. Brazilian Annals of Dermatology, 79, 91-99.
Veloz, M.C.T., Nascimento-Schulze, C.M., \& Camargo, B.V. (1999). Social representations of aging. Psychology: Reflection and Critique, 12, 470-501.

Veras, R.P., Ramos, L.R., \& Kalache, A. (1987). Growth in the elderly population in Brazil: Transformations and consequences in society. Public Health Review, 21, 225-233.

Received January, 25, 2006 Review received May, 19, 2006 Accepted November, 30, 2006 